\title{
Internacionalização da educação superior: Processo de Bolonha
}

- Hamilton de Godoy Wielewicki "

—arlize Rubin Oliveira**

\section{Resumo}

A transição para o século XXI é marcada por profundas mudanças nas relações da sociedade. A educação é parte desse processo e, neste sentido, a relação indissociável entre a unificação da Europa e a de sua educação superior denota tal percepção. Este trabalho objetiva trazer elementos para a compreensão do Processo de Bolonha, analisando aspectos de sua implementação; estabelecendo vínculos entre suas características e objetivos e a racionalidade à qual o Processo parece estar afiliado; e indicando possiveis impactos para a educação superior brasileira. A análise indica que, na medida em que a Europa deseja estabelecer parcerias internacionais que ampliem seu leque de opções para a educação superior, pode-se presumir que a pauta tende a apontar para interesses da própria Europa. Isso exige uma postura de discussão e negociação que tenha como base as noções de alteridade e diversidade, com a universidade como locus privilegiado de análise crítica, propositiva e, sobretudo, prospectiva.

Palavras-chave: Processo de Bolonha. Internacionalização. Educação superior.

\section{Internationalization of higher education: the Bologna Process Abstract:}

The transition to the XXI Century has deeply changed relationships within society. Education is part of such process and, thus, the relationship between the process of unification of Europe itself and of its Higher Education is emblematic of such perception. This paper aims to bring about elements to understand the Bologna Process; analyzing aspects of its implementation; seeking for links between its

\footnotetext{
Doutor em Educação, Universidade Federal do Rio Grande do Sul (UFRGS); Professor Assistente, Universidade Federal de Santa Maria (UFSM); bolsista CAPES-PICDT/PDEE 2009. E-mail: hgw@smail.ufsm.br

*" Doutoranda do Programa de Pós-Graduação em Educação (PPGEdu), UFRGS; Professora Assistente, Universidade Tecnológica Federal do Paraná (UTFPR), Campus Pato Branco; bolsista CAPES-PIQDTec. Email: rubin@utfpr.edu.br.
} 
characteristics and the goals and reasoning underlying that Process; and discuss likely impacts upon the Brazilian context. Our analysis indicates that as Europe aims to establish international partnerships to widen the scope of options for its higher education, one can assume that the agenda to be proposed tends to be screened by European interests. That, in its turn, requires some discussion and negotiation that foregrounds the notions of otherness and diversity, with the university fully performing its condition of privileged locus for critical, propositional and prospective analysis.

Keywords: Bologna Process. Internationalization. Higher education

\section{Internacionalización de la educación superior: el Proceso de Bologna Resumen}

La transición hacia el siglo XXI ha sido marcada por profundos cambios en la sociedad. La educación es parte de eso y el proceso de unificación de Europa e lo de su educación superior es emblemática de esa percepción. Este trabajo busca traer elementos para la comprensión del Proceso de Bologna, analizando aspectos de su implementación; buscando establecer vínculos entre sus características e objetivos y la racionalidad a la cual el Proceso parece estar ahijado. De ese modo, consideramos impactos de Bologna en el escenario de la educación superior brasileña. El análisis emprendido indica que mientras Europa manifiesta su intento de establecer parcerías internacionales que se le garantice un abanico de opciones más amplio para la educación superior, el interés de Europa debe hablar más fuerte. Eso exige discusión y negociación basada en las nociones de alteridad y diversidad, con la universidad en condición de locus de análisis crítica, prepositiva e, además, prospectiva.

Palabras clave: Proceso de Bologna. Internacionalización. Educación superior.

\section{Introdução}

A transição para o século XXI, longe de ser apenas um marco cronológico, tem sido marcada por profundas mudanças na humanidade, na natureza e nas relações delas emanadas. A educação, de maneira geral, e a educação superior, objeto desta análise, encontra-se imbricada nesse processo. Assim, a relação indissociável entre 0 processo de unificação da Europa e o de unificação da educação superior europeia é emblemática dessa percepção.

0 estudo aqui reportado teve início no primeiro semestre de 2007, a partir de uma das atividades da linha de pesquisa Universidade: Teoria e Prática, referida ao Programa de Pós-Graduação em Educação da Universidade Federal do Rio Grande do Sul (PPGE- 
du-UFRGS). Na ocasião, reiterando a preocupação da linha com as questões atinentes à internacionalização da educação superior, as análises e sínteses relativas à criação de uma Área de Educação Superior Europeia, através do chamado Processo de Bolonha, permitiram observar a importância de tal processo, não apenas no âmbito da educação europeia, mas também possiveis implicações e intenções em relação ao resto do mundo. Por outro lado, a maioria dos trabalhos disponiveis sobre Bolonha naquele momento se mostravam mais como relatos do andamento do processo do que como discussões centradas nos conceitos, ideias e racionalidades que dão sustentação ao próprio processo. Em função disso, nos sentimos instigados a buscar - e elegemos como objetivo deste trabalho - uma compreensão mais direcionada aos aspectos ontológicos do Processo de Bolonha, que permita visualizar que ideias parecem sustentar a busca de uma Europa do conhecimento, tal qual almejada e explicitada nos documentos formais do processo.

Para tanto, tomamos como metodologia de estudo uma análise que considera como ponto de partida os comunicados, frutos dos encontros oficiais de acompanhamento, implementação, avaliação e deliberação do Processo de Bolonha. Tal análise está estruturada em três grandes eixos: o delineamento do contexto, no qual o Processo de Bolonha se insere, uma breve síntese dos principais eventos, documentos e inquietações sobre esse Processo e, por fim, nas possíveis implicações de Bolonha para a Educação Superior brasileira.

\section{Delineando o contexto no qual o processo de Bolonha se insere}

Sob qualquer perspectiva, o mundo passou por profundas transformações sociais, políticas e econômicas em torno da virada do segundo para o terceiro milênio. Nesse contexto de transformação, a reestruturação econômica vivenciada na transição para o século XXI refletiu, segundo Burbules e Torres (2004), algumas tendências, dentre as quais se acentuam a globalização da economia, acompanhada por um fluxo transnacional de capitais e o estabelecimento de novas relações e acordos comerciais entre paises, resultando num processo incontestável de internacionalização do comércio, com a quebra de barreiras e entraves ao livre trânsito de mercadorias. Essa economia globalizada, a seu turno, resulta na reestruturação do mercado de trabalho, determinando novas relações entre capital e trabalho, num jogo de forças em que a flexibilização reforça - de distintos modos - os interesses do capital. Ainda assim, na linha do que argumentam, por exemplo, Apple (2007) e Santos (2006), a perspectiva aqui adotada é a de ao menos considerar as múltiplas experiências alternativas locais como uma possibilidade concreta (embora complexa) de mudança desse panorama global.

Além disso, o aumento do tamanho e da importância do setor de serviços (em detrimento dos setores primário e secundário) responde também - segundo esses autores - pela ascensão de novas forças produtivas, com uma crescente importância da produção intensiva 
de capital e um também crescente abismo financeiro, tecnológico e cultural entre os paises desenvolvidos e os menos desenvolvidos, tudo isso possibilitado - ou ao menos facilitado pelo aporte intensivo das novas tecnologias de informação, num processo cujos impactos e desdobramentos ainda podem estar longe de uma compreensão mais plena.

No que concerne aos vínculos históricos mais recentes deste contexto de mudança global da virada do século, parece haver poucas dúvidas quanto à relevância de dois marcos: as transformações políticas do período pós II Guerra Mundial e a queda do Muro de Berlim (em 1989), ambos passiveis de referência a um modo de organização política, econômica e social característicos de um pensar e de um agir que sublimam a perspectiva do ocidente.

Em relação ao período pós II Guerra Mundial, as relações que se estabeleceram, principalmente na Europa, determinaram uma práxis então não vivenciada no campo das políticas internacionais. Pode-se argumentar que tal práxis - marcada pela polarização entre dois blocos pretensamente opostos - era marcada, não só, por aspectos diferenciais de cada bloco, mas pela gênese comum de uma racionalidade eurocêntrica. Nesse sentido, Santos (2006, p. 217) postula que mesmo o Manifesto Comunista não deixa de ser

[...] um documento eurocêntrico que transmite uma fé inabalável no progresso, saúda a burguesia como classe revolucionária que o tornou possivel, $\mathrm{e}$, por essa razão, profetiza a derrota da burguesia face ao proletariado como classe emergente capaz de garantir a continuidade para além dos limites burgueses,

isto é, projeta uma nova sociedade sem romper, contudo, com os fundamentos da racionalidade que tem a Europa como valor e princípio, em que pese as distinções fundamentais entre tais projetos de sociedade, conforme também salientado por Popkewitz e Brennan (1998).

Para além das distinções entre os dois blocos, há que se mencionar também que, mesmo dentro do bloco alinhando os paises capitalistas, divergências internas e interesses conflitantes ajudaram a criar as condições ideais para a emergência dos Estados Unidos como potência mundial que disputa - e eventualmente conquista a hegemonia'. A educação, a ciência e a tecnologia tiveram papel crucial na construção desse projeto hegemônico. Nesta disputa de forças, os Estados Unidos despontaram como potência, principalmente pela confluência de seus projetos de ciência, educação e tecnologia, entre outros.

0 contexto geopolítico do pós-guerra é altamente complexo e exigiria a consideração de inúmeros outros fatores e nações (como por exemplo, a China, a constituição do bloco soviético e os movimentos anticolonialistas). Dados os objetivos do presente texto, no entanto, vamos nos ater às questões que mantém uma relação mais estreita com a construção do Processo de Bolonha. 
Diante da complexidade da temática atinente às configurações do cenário mundial e levando em conta o espaço limitado para explicitar todos (ou até mesmo uma parcela mais substancial os) fatores envolvidos no processo, o objetivo proposto para este texto está centrado na discussão que diz respeito ao cenário educacional, mais especificamente, no que concerne à Educação Superior. Portanto, com o objetivo de situar a questão da educação superior, alguns marcos fundamentais do contexto das novas configurações são trazidos com intento de - reiteramos - tão somente situar o objeto de estudo em seu contexto.

Um dos marcos fundamentais no contexto das novas configurações das políticas internacionais pode ser considerado o tratado assinado em 1949 por 10 paises, instituindo o Conselho da Europa. 0 tratado tinha como objetivos realizar a união estreita entre paises membros, salvaguardar ideais e princípios que são patrimônio comum e favorecer o progresso econômico e social de uma Europa arrasada pela guerra. 0 processo de integração europeia se estabelece, então, a partir da necessidade de reconstruir a Europa como espaço político e econômico e assim, transformando-se em 'modelo' para o mundo, mesmo compreendendo os controversos sentidos do que se entenda por modelo.

Na segunda metade do século XX várias ações ocorreram em direção à construção da chamada União Europeia 0 ideal postulado era construir um modelo federativo que permitisse a integração das economias exauridas do pós-guerra. É possivel inferir também que tal integração presumia uma Europa unificada e fortalecida, sem, entretanto, potencializar a ascensão de Estados nacionais que reivindicassem prevalência sobre os demais paises da Europa. Tentava-se, dessa forma, afastar os perigos que foram determinantes para a eclosão dos dois grandes conflitos do século XX e que tiveram - não por acaso - como palco central a Europa.

Assim, após um longo e exaustivo processo, marcado por várias etapas intermediárias, com avanços e recuos táticos, em 1993, a União Europeia é institucionalizada com os objetivos de: promover a unidade política e econômica da Europa; melhorar as condições de vida e de trabalho dos cidadãos europeus; melhorar as condições de livre comércio entre paises membros; reduzir desigualdades sociais e econômicas entre as regiões; fomentar o desenvolvimento econômico dos países em fase de crescimento; e proporcionar ambiente de paz, harmonia e equilibrio na Europa².

No entanto, a compreensão desse movimento de integração, presume entendêlo não somente dentro do cenário da superação de um grande conflito (a II Guerra Mundial) com impactos diretos sobre a Europa, mas sobretudo a partir da perspectiva de como tal conflito se insere numa lógica ou racionalidade que permita um olhar mais profundo e complexo sobre os fenômenos em pauta. Isso implica buscar,

${ }^{2}$ Informações mais detalhadas sobre os objetivos da União Europeia estão disponíveis em Europa (2010). 
portanto, as conexões entre esse movimento de integração (e tantos outros ao longo dos três últimos séculos) e a racionalidade que o permeia.

Salvo melhor juizo, estamos tratando, portanto, do modelo de verdade e ciência cujo marco divisório inicial mais visível é a Revolução Industrial do século XVIII Esse modelo tem como berço a Europa e tem na sua base uma ideia de humanidade e de sociedade filiável a um padrão eurocêntrico. Assim, presumimos aqui que a Europa como 'modelo' para o mundo não pode ser vista como algo que ocorre a partir dos acordos da União Europeia, mas prototípico de uma racionalidade cuja base pode ser considerada a assim chamada racionalidade moderna.

Para Santos (1997) as principais características dessa racionalidade moderna, por ele denominada de paradigma dominante, são: o espaço definido pela geometria, homogêneo, sem distinções qualitativas; a purificação das qualidades sensoriais dos objetos investigados (neutralidade); as definições por propriedades objetivas gerais (massa, volume, figura); a presunção da obediência de astros e corpos terrestres às mesmas leis universais da física; a articulação da natureza por relações de causa e efeito; e a suposição da natureza ser a mesma em toda a parte, não existindo graus de imperfeição-perfeição e inferioridade-superioridade.

Essas caracteristicas do fazer científico, construídas a partir das ciências naturais e exatas, assumem para Santos (2006) também uma dimensão sociocultural. 0 autor fala da modernidade ocidental como um paradigma sociocultural que se constituiu a partir do século XVI e se consolidou entre finais do século XVII e meados do século XIX como projeto hegemônico.

Santos (2006) distingue ainda a modernidade em dois pilares em tensão dialética, o pilar da regulação social e o pilar da emancipação social. No entanto, na compreensão do autor, esses pilares são adequados para a realidade europeia, mas não necessariamente adequados às realidades extraeuropeias para onde se expandiu a Europa. Santos (2006) chama a atenção para a regulação social que assenta em três princípios: do Estado, do mercado e da comunidade. Esses princípios não dão conta das formas de (des)regulação colonial onde o Estado é estrangeiro, o mercado inclui pessoas entre mercadorias (os escravos) e as comunidades são arrasadas em nome do capitalismo e da missão civilizadora. Assim, a noção de comunidade é substituída por uma minúscula sociedade civil racializada, criada pelo Estado e constituída por colonos, pelos seus descendentes e por uma minoria de assimilados.

A discussão proposta por Santos (2006) permite ponderar sobre dois aspectos que, embora possam parecer distintos, neste contexto estão visceralmente ligados. De um lado, a consideração de que o 'modelo para o mundo' é, na prática, imposto historicamente ao mundo pela Europa. Por outro lado, a negação de toda e qualquer forma de organização humana que se seja distinta desse 'modelo' imposto. 
Neste processo, civilizações foram dizimadas em nome de um projeto de sociedade em que os princípios da modernidade foram assentados em ideais de liberdade, igualdade e solidariedade referidos ao 'modelo' imposto, à revelia do significado que tais princípios pudessem ter para tais civilizações. Dito de outra forma, escraviza-se em nome da liberdade, aniquilam-se as diferenças em nome da igualdade e afronta-se a soberania em nome da solidariedade com o colonizador.

Mesmo tendo presente a complexidade das relações que configuraram o processo de organização social e política que pauta o modelo de racionalidade que se configurou a partir da chamada Revolução Científica, algumas inferências são possiveis quanto a seus desdobramentos, dentre eles, a ideia de verdade única (a ciência), a expansão do capitalismo impulsionado pelas grandes navegações e pelo desenvolvimento científico e a expropriação da natureza e da humanidade desse contexto.

No âmbito da racionalidade hegemônica essa ordem social é concebida não apenas como a desejável, mas principalmente pela sua colocação (e construção) como a única possível. No entanto Lander (2005) alerta que a naturalização da sociedade liberal como a forma mais avançada e normal de existência humana não é - como já apontamos anteriormente - uma construção recente que possa ser atribuida somente ao pensamento neoliberal ou à atual conjuntura política. Pelo contrário, trata-se de uma ideia com uma história no âmbito do pensamento social ocidental dos últimos séculos. Ou seja, na medida em que esse projeto liberal (ou neoliberal) de sociedade se consubstancia numa forma de globalização hegemônica, suas relações com um processo de internacionalização da educação superior passam a se configurar de um modo cada vez mais interdependente.

Para Lander (2005) existe uma extraordinária continuidade entre as diferentes formas através das quais os conhecimentos eurocêntricos legitimaram a missão civilizadora ou normatizadora a partir das deficiências - desvios em relação ao padrão normal civilizado - de outras sociedades. Os diferentes recursos históricos (evangelização, civilização, o fardo do homem branco, modernização, desenvolvimento, globalização) têm todos como sustentáculo a concepção de que há um padrão civilizatório que é simultaneamente superior e normal.

Hoje, passados quatro séculos desse marco 'civilizatório' vários são aqueles que afirmam o esgotamento da racionalidade moderna. Há, também, os que argumentaram que chegamos ao fim da história. No entanto, a análise aqui empreendida toma um caminho distinto desses, na medida em que busca, na reflexão sobre alguns movimentos atuais como, por exemplo, o projeto de unificação da Educação Superior da Europa, traços de tal racionalidade. 
Diante de tal quadro, o Processo de Bolonha (BOLOGNA..., 2009) ocupa um papel de crescente destaque nas discussões acerca do ensino superior, não apenas na Europa, mas também no contexto mundial. Podem-se empreender distintas análises sobre esse processo, mas é cada vez mais difícil ignorar sua força e impacto. A dimensão que ocupa hoje a Declaração de Bolonha está visceralmente relacionada ao contexto no qual esse acordo ganha existência.

A compreensão da gênese da racionalidade dominante nos coloca diante de indagações que, mesmo difíceis de serem respondidas, nos remetem a uma reflexão estruturada a partir de outro ponto de partida. Dessa forma, se partirmos da premissa que 0 modelo de ciência e sociedade proposto a partir da Revolução Científica do século XVIII possa não estar esgotado, caberia questionar quais seriam, afinal, as bases do projeto de unificação da Europa e, consequentemente, do chamado Processo de Bolonha.

Não temos - é importante frisar - a pretensão de responder a esta questão. Temos, entretanto, o propósito de, a partir de um quadro referido ao contexto do modelo de racionalidade dominante, refletir sobre o Processo de Bolonha, um movimento de relevância, nascido na Europa e cujos reflexos já podem ser percebidos, inclusive para além dela própria.

Assim, ponderamos que, em larga medida, a partir desse modelo de racionalidade dominante, os últimos 50 anos do século XX podem ser considerados como o ápice do projeto da ciência moderna. Transformações e (re)significações ocorreram em todas as esferas da sociedade. Os impactos das novas configurações levaram à reestruturação econômica e à redução do estado como o modelo hegemônico de desenvolvimento. Nesse sentido, a lógica do estado mínimo configurou-se com fortes reduções dos benefícios do estado do bem estar social (welfare state), cujos impactos principais (e talvez mais nefastos) vão ser mais nitidamente perceptíveis sobre as áreas da saúde, habitação e educação.

Em termos educacionais o período ao redor das décadas de 1980 e 1990 é marcado pela eclosão de um movimento de reformas educacionais por todo o mundo, instaurando aquilo que Hargreaves e outros (2002) denominam de 'nova ortodoxia oficial', um movimento que é caracterizado pela padronização em torno de políticas de avaliação, de financiamento, de formação de professores e de currículo, num processo de nítida sintonia entre tais políticas e a visão de desenvolvimento preconizada por grandes organismos financeiros internacionais como, por exemplo, o Banco Mundial.

Tal situação, aliada às transformações no panorama político internacional (dentre as quais poderíamos citar várias, mas destacamos, por seu valor simbólico, a derrocada do bloco comunista do Leste Europeu), acaba por gerar, de acordo com Carr (2003) um processo de ofuscamento de diferenças e de fronteiras entre os 
projetos de Estado, tornando mais difícil distinguir, a partir das diretrizes de governo para a educação, a essência ou natureza política de tal projeto, ou, dito de outra forma, perceber como se distinguem, do ponto de vista de seu projeto para a educação, por exemplo, o que foi feito pelo governo trabalhista e pelo governo conservador na Inglaterra. Assim, se durante algum tempo foi possivel operar distinções a partir de categorias como direita/esquerda ou conservador/ progressista, cada vez mais, segundo o argumento de Carr (2003) tais distinções vão ser referidas às bases do pensamento filosófico ocidental, ou seja, a Sócrates, Platão e Aristóteles. Um argumento interessante que Carr traz à cena é a possibilidade de que os rótulos imediatos não sejam suficientes para operacionalizar uma distinção e, nesse sentido, um recurso para tornar factivel, ao menos, alguma distinção entre tais projetos.

Por entendermos a natureza controversa de tal posição, vamos destacar dela apenas a constatação de que a racionalidade que permeia nossa ação diante do mundo e que busca se constituir como força hegemônica é basicamente ocidental, eurocêntrica e constituída a partir de ideais de humanidade que excluem como possibilidade qualquer valor fora desse padrão ou ideal. Com isso, incorremos, como argumenta Santos (2000), num desperdício da experiência que possa, mesmo com pertinência, confrontar essa força hegemônica. Tal constatação é particularmente útil para entendermos - conforme argumentamos anteriormente - em que bases e a partir de quais referenciais ocorre a instauração do projeto de ciência moderna a partir do século XVII.

Diante dessa realidade social e política, que (re)significou os conceitos de sociedade, estado, nação e até mesmo de humanidade, algumas questões se colocam com muito vigor no cenário europeu e assumem uma posição de centralidade no debate a partir do ponto de vista da própria Europa, dentre as quais a documentação sobre o contexto que desencadeia o Processo de Bolonha aponta três: 1) Como a Europa se prepara para conciliar novas demandas (de um estado mínimo e mais competitivo) e o desejo de manter direitos sociais?; 2) Como enfrentar a perda de competitividade e atratividade da Educação Superior Europeia, em relação ao restante do mundo e, de forma especial, aos Estados Unidos?; e 3) Como reconquistar o papel de ponta das universidades europeias na produção de conhecimento e ser a Europa do Conhecimento? Ao que parece, a tentativa de resposta a essas três perguntas passa pelo chamado Processo de Bolonha.

\section{Sintetizando e discutindo o Processo de Bolonha}

Para discutir as bases e características do Processo de Bolonha, optamos por apresentar uma sintese histórica desse processo, inclusive por entendermos que, para os objetivos aqui propostos, seria desnecessário historiar exaustivamente 0 Processo como um todo, o que já foi realizado por Erichsen (2007), Bastos (2008), 
Dias Sobrinho (2008), Lima, Azevedo e Catani (2008) entre outros. Em nossa síntese, no entanto, vamos pontuar os elementos que ilustram o argumento de que o Processo de Bolonha busca resgatar, pelo viés da Europa do Conhecimento, a racionalidade eurocêntrica.

0 chamado Processo de Bolonha tem seu marco inicial em 1998, quando ocorre um encontro de ministros da educação de quatro países europeus (Alemanha, França, Itália e Reino Unido), culminando na Declaração de Sorbonne, que evidencia o papel preponderante das universidades no desenvolvimento da dimensão cultural da Europa, conclamando as nações européias a

criar uma área europeia do ensino superior onde as identidades nacionais e os interesses comuns possam interagir e reforçar-se mutuamente para benefício da Europa, dos seus estudantes e na generalidade dos seus cidadãos (SORBONNE, 1998, não paginado).

Em 1999, um novo encontro, então, com 29 países, resulta na Declaração de Bolonha, com o objetivo explícito de construir um espaço europeu de ensino superior e conduzir a uma Europa da ciência e do conhecimento. As prioridades assinadas naquela declaração foram: a adoção de um sistema convergente de graus acadêmicos entre os países, adoção de um sistema de educação superior em dois ciclos, o estabelecimento e generalização de um sistema de créditos acumuláveis, a promoção de mobilidade acadêmica, a garantia de qualidade e o incremento da dimensão europeia da educação superior.

Na Declaração de Bolonha (1999) se destacam uma posição de resguardo da importância da Europa (e em especial desses quatro países) na história da educação superior, bem como o desejo manifesto de retomada desse papel preponderante através da criação de uma área dedicada ao ensino superior que pudesse funcionar como o caminho para: 1) a livre circulação dos cidadãos; 2) a oportunidade ampliada de emprego; e 3) o desenvolvimento do continente europeu como um todo ${ }^{3}$. Dentre outras questões, a explicitação dessas três intenções dá margem para interpretar o Processo de Bolonha como uma comoditização da educação superior, que estaria tendo um tratamento como bem (e não como direito) capaz de auxiliar na restauração da competitividade européia e, talvez não sem razão, atraindo críticas substantivas ao Processo conforme, por exemplo, Lima, Azevedo e Catani (2008). 0 aligeiramento da formação e a possibilidade de agregar "competências" ao percurso formativo podem ser vistos, nesse sentido, como elementos prototípicos desse alinhamento.

\footnotetext{
${ }^{3}$ Os fatos e eventos relativos ao processo de Bolonha como um todo, bem como uma base documental extensiva podem ser encontrados em Portugal (2008) e no sítio oficial que trata da situação do Processo de Londres em diante (BOLOGNA ..., 2009) ou, de modo mais sintético, em Erichsen (2007).
} 
0 andamento do Processo de Bolonha, dadas as razões já expostas aqui, é acompanhado e monitorado de perto, conforme acentuam Lima, Azevedo e Catani $(2008$, p. 13) pelos Ministros da Educação dos paises envolvidos. A leitura dos comunicados e relatórios permite visualizar o caminho percorrido, a partir da perspectiva oficial do processo, em seu contexto. Os comprometimentos e ações mutuamente pactuadas (presentes nos comunicados) também permitem perceber, ainda que superficialmente, os avanços e estrangulamentos do Processo.

Com a intenção de proporcionar uma visão geral, organizamos o quadro sínte$\mathrm{se}^{4}$ apresentado a seguir, que situa cronologicamente os pontos de destaque do Processo de Bolonha, de 1999 até 2007.

\begin{tabular}{|l|l|l|}
\hline Data & Documento & Pontos de destaque \\
\hline 1999 & $\begin{array}{l}\text { Declaração } \\
\text { de Bolonha }\end{array}$ & $\begin{array}{l}\text { Necessidade de retomar o papel da Europa na Educação Superior no } \\
\text { contexto global - a Europa do conhecimento. }\end{array}$ \\
\hline 2000 & Projeto Tuning & Projeto piloto para sintonizar as estruturas educativas da Europa. \\
\hline 2003 & $\begin{array}{l}\text { Comunicado } \\
\text { de Praga }\end{array}$ & $\begin{array}{l}\text { Indicação de três linhas de ação: 1) Aprendizagem ao longo da vida; } \\
\text { 2)envolvimento dos estudantes na gestão; 3) promoção da atividade do } \\
\text { espaço europeu de ES. }\end{array}$ \\
\hline 2005 & $\begin{array}{l}\text { Reafirma objetivos de Bolonha e Praga e adiciona: 1) Vínculos mais } \\
\text { estreitos entre ES e pesquisa;2) ampliação do sistema de 2 ciclos, inclu- } \\
\text { indo um terceiro, para doutoramento e cooperação pós-doutoramen- } \\
\text { to. Defesa da diversidade dos perfis acadêmicos. Dilema - convergência } \\
\text { x padronização. }\end{array}$ \\
\hline 2009 & $\begin{array}{l}\text { Ministros desejam, até 2007, avançar, nos seguintes aspectos:Elaboração } \\
\text { das referências e das linhas de orientação para a garantia da qualida- } \\
\text { de, tal como proposto pelo relatório da ENOA (rede europeia para a } \\
\text { garantia da qualidade no ensino superior);estabelecimento dos qua- } \\
\text { dros nacionais de qualificações;emissão e reconhecimento de diplomas } \\
\text { conjuntos, incluindo em nivel de doutoramento;criação de oportunida- } \\
\text { des para percursos flexiveis de formação no ensino superior, incluindo } \\
\text { existência de disposições para validação dos acervos. }\end{array}$ \\
\hline de Louvain & $\begin{array}{l}\text { Esforços de avanço na questão de mobilidade e comparabilidade da } \\
\text { certificação são reportados e reiterados.Internacionalização ganha des- } \\
\text { taque tanto no relato como nos compromissos futuros.Dimensões de } \\
\text { qualidade da UNESCO e OCDE como parâmetro para diálogo } \\
\text { internacional.Empregabilidade dos egressos como uma questão } \\
\text { central.Retomar a visão inicial do Processo como pauta para os desafios } \\
\text { futuros, para além de estruturase ferramentas. }\end{array}$ \\
\hline $\begin{array}{l}\text { Balanço positivo da primeira década do Processo.Reiterados os funda- } \\
\text { mentos do Processo de Bolonha como base para a pauta até 2020. } \\
\text { Termos presentes (em contraposição à crise econômica atual): inova- } \\
\text { ção, criatividade, modernização. Autonomia universitária indissociável } \\
\text { de financiamento público à ES. }\end{array}$ \\
\hline
\end{tabular}

Quadro 1: Quadro síntese: Processo de Bolonha.

Fonte: Adaptado pelo autor (2009).

\footnotetext{
4 As informações contidas no quadro síntese foram obtidas nos diversos documentos disponíveis a partir de Portugal (2008) e listados nas referências do presente texto.
} 
Na medida em que o Processo avança e que se busca uma ampliação de sua abrangência, os encontros formais de acompanhamento, particularmente os de Praga (A CAMINHO..., 2001), Berlim (PORTUGAL, 2003) e Bergen (BOLOGNA..., 2005), parecem mais focados em construir uma agenda possível para um número crescente de países participantes. 0 desafio de contrabalançar convergências e riscos de padronização de sistemas sabidamente marcados por um alto nível de diversidade passa a ser enfrentado pela produção de uma política (ou conjunto de políticas) de características transnacionais. Tais políticas, por sua vez, enfrentam distintos niveis de resistência, aparentemente mais fortes na academia do que na arena política, inclusive pela perda de protagonismo das universidades nesse processo.

Assim, se compararmos os comunicados iniciais com os mais recentes, pelo menos dois fatos se salientam: 1) um processo de unificação de tamanha envergadura e complexidade, mesmo conduzido a partir de uma nítida visão hierárquica - na qual os interesses da Europa devem prevalecer sobre aqueles de cada país membro - demanda tempo e arranjos sociopolíticos de igual complexidade; e 2) os impactos desse processo podem ser maiores do que os inicialmente esperados ou explicitados.

No que se refere à complexidade e aos arranjos para dar conta da implementação da área de educação superior europeia, Lima, Azevedo e Catani (2008, p. 12-13) alertam que a implementação do Processo de Bolonha traz consigo a "redução da autonomia relativa dos estados nacionais em matéria de educação superior", que se vê reposta por "uma direção supranacional de políticas, agora relativamente descontextualizadas"; com consequente "deslocalização das arenas de debate e dos processos de discussão democrática de tipo tradicional". Há no alerta daqueles autores, no entanto, um elemento já indicado por Veiga e Amaral (2006, p. 283), que diz respeito "à não participação ou a uma participação fluida e difusa dos atores educativos diretamente envolvidos, em favor da intervenção de stakeholders altamente organizados e institucionalizados", abrindo margem "à emergência de novas tecnoestruturas e especialistas (gestores, grupos de missão, peritos e avaliadores profissionais etc.)".

Há, no entanto, implementações efetivas do processo, que se referem à comparabilidade dos sistemas e da acreditação, à mobilidade acadêmica e, mais recentemente, às medidas de estímulo à participação estudantil e, em menor grau, a um entendimento comum sobre 0 que se concebe como qualidade para, no e do ensino superior. Isso, por sua vez, permite antever a preconizada área de Educação Superior Europeia com construção unitária em seus aspectos estruturais, mas marcada pela diversidade em aspectos diferenciais. 0 comunicado de Londres (BOLOGNA..., 2007) abre margem para uma interpretação de que, diante da consolidação dos princípios iniciais do Processo de Bolonha, o foco volta-se de modo mais explícito para a internacionalização como meta de imediata relevância. Parece haver, portanto, a pavimentação do caminho para a mobilidade acadêmica no âmbito da Europa e, dependendo de desdobramentos e articulações internacionais, com o resto do mundo. 
A busca de convergência e comparabilidade entre sistemas implica também a necessidade de identificar parâmetros convergentes de avaliação, uma tarefa que é sensivelmente dificultada pela carência ou ausência de indicadores comuns. A dificuldade reside então no fato de que uma relação mais harmônica entre avaliação, planejamento e desenvolvimento envolve a construção de indicadores que tenham sentido para os contextos nos quais a avaliação é implementada. Pode-se especular que na medida em que haja maior convergência e mobilidade entre os sistemas de Educação Superior europeus, um maior nivel de compartilhamento de objetivos tende a ocorrer e, em consequência disso, podem aflorar categorias de indicadores mais fortemente relacionados entre si.

Uma outra fonte de inquietação intrínseca ao Processo diz respeito à relação conflituosa entre a implementação do Processo (que, vale lembrar, envolve o diálogo entre sistemas) e a autonomia universitária (cuja expressão prototípica se dá em nível institucional). Coloca-se, portanto, um dilema entre conformação - ou seja, o atendimento formal dos requisitos e normativas propostos - e aderência - a incorporação mais intrínseca da lógica que move o processo.

A implementação do Processo de Bolonha, até mesmo em função de seus impactos e desdobramentos, não está infensa a críticas e a posicionamentos contrários no próprio escopo dos paises a ele adscritos. A primeira crítica que se pode pensar, consoantemente com Veiga e Amaral (2006, p. 286) diz respeito ao Processo de Bolonha ter objetivos caracteristicamente múltiplos (uma vez que são almejadas muitas coisas ao mesmo tempo), conflitantes (já que coisas diferentes são almejadas) e vagos (para permitir que se prossiga, apesar das diferenças), ou seja, são criticas que primariamente referem-se à processualidade em si, mas que não deixam de ter relação com seus objetivos.

Há ainda algumas dificuldades inerentes a um processo que (tal qual Bolonha) impacta, ao mesmo tempo, o âmbito local, nacional e internacional, isto é, trata-se de um acordo construído a partir de um entendimento entre nações, com características de processo decisório de base descendente (top-down) mas que exige, entretanto, uma visão coordenada, uma vez que ganha materialidade também - e de forma simultânea - ao nível dos diferentes sistemas nacionais e das instituições de educação superior envolvidos. Na mesma direção, Kettunen e Kantola (2006) alertam para os problemas derivados da distância entre o nivel de formulação e os respectivos niveis de implementação das decisões. Relacionada a essa percepção, pode-se argumentar também que o modelo de implementação top-down é altamente complexificado - e talvez comprometido - pela falta de participação estudantil, a ponto da necessidade de tal participação ser pautada a partir dos comunicados oficiais de Berlin (PORTUGAL, 2003), com menção de avanço de resultados no documento de Londres (BOLOGNA..., 2007). 
Há também questionamento, conforme alertam Veiga e Amaral (2006, p. 288) quanto ao uso do Processo de Bolonha como alavanca para promoção de reformas que os paises tinham dificuldade de fazer passar, ou seja, usa-se o relativo consenso produzido no âmbito da negociação diplomática genérica para a implementação de medidas acadêmicas e administrativas de cunho mais específico (nem sempre palatáveis internamente) sob a alegação de uma pretensa adesão a acordos que transcendem as fronteiras nacionais.

Assim, sem ter a pretensão de atribuir ao Processo de Bolonha uma caracterização que exacerbe intenções explicitadas pelos documentos até aqui constituídos, aventamos - com a prudência que as circunstâncias exigem - a possibilidade de que tal Processo traga - com (re)significações - a lógica da racionalidade que constitui o padrão civilizatório ao qual nos referimos.

Por fim, parece haver pouca permeabilidade do Processo como um todo, que permita refazer algumas das rotas adotadas. Essa baixa permeabilidade parece sustentar-se em justificativas tautológicas que defendem que Bolonha é um processo necessário porque é importante para a Europa e que é importante para a Europa porque é necessário.

\section{Implicações do Processo de Bolonha}

Concretamente, os impactos de Bolonha já são visiveis no espaço da educação superior brasileira, ainda que, muitas vezes, carecendo de debate e explicitação. Prototipicamente, dois movimentos importantes estão (ou dependendo de como se encare a questão, foram) colocados na agenda: o projeto Universidade Nova, da Universidade Federal da Bahia (UFBa) e o Programa de Apoio a Planos de Reestruturação e Expansão das Universidades Federais (REUNI).

A proposta chamada de Universidade Nova foi concebida em 2006 pela UFBa, sendo pautada teoricamente nas ideias de Anísio Teixeira e estruturalmente no Projeto de Lei da Reforma da Educação Superior (mais especificamente na alegada lacuna do projeto quanto à arquitetura acadêmica) e nos fundamentos da unificação da educação superior europeia representado pelo Processo de Bolonha. Dentre os pontos de destaque da proposta da Universidade Nova estão a organização em dois ciclos: um primeiro, de formação geral, estruturado em torno de Bacharelados Interdisciplinares e o segundo, voltado para a formação acadêmica e profissional. Embora faça um alinhamento com as bases do Processo de Bolonha, a proposta argumenta ter uma organização menos nitidamente disciplinar, ainda que com pontos de comunicação com aquela estrutura. Além disso, seus proponentes alegam que a Universidade Nova não é "nem Harvard, nem Bolonha", mas um modelo de estruturação da educação superior sensivel ao pensamento anisiano tardio e à realidade brasileira. 
Uma outra perspectiva de crítica sobre a Universidade Nova é trazida por Lima, Azevedo e Catani (2008, p. 27), que argumentam que

A lógica da Universidade Nova pode ser compreendida como um modo de se afastar do Processo Bolonha e se reaproximar do modelo norte-americano (não totalmente implantado em 1968), isto sem precisar montar a infraestrutura necessária da universidade norte-americana e sem a necessidade de encaminhar a formação profissional na graduação como, de fato, continua acontecendo na Europa do Processo de Bolonha.

A proposta recebe, portanto, críticas tanto por aquilo que ela é, quanto por aquilo que ela representa. Ao delinear um modelo (ou, nos termos da proposta, arquitetura curricular) de universidade que converge para o Processo de Bolonha (visão com presença marcante no projeto de Lei de Reforma da Educação Superior proposto pelo governo) ${ }^{5}$, é criticada por sua inscrição naquele modelo. Por tal inscrição, filia-se, por extensão - e a despeito das diferenças que procura demarcar - não somente a um modelo de universidade, mas, de modo contundente, a uma opção de internacionalização filiada a um modelo específico de racionalidade. E, ao incorporar as virtudes e limites dessa racionalidade, é alvo de críticas por aquilo que representa.

O Programa de Apoio a Planos de Reestruturação e Expansão das Universidades Federais (REUNI), por sua vez, acresce aos referenciais presentes no projeto Universidade Nova os meios e os mecanismos de financiamento da educação superior, o que leva a uma adesão maciça das instituições federais de educação superior (IFES), em meio a questionamentos múltiplos sobre a celeridade, a insuficiência e até mesmo a ausência de debate. Questionamentos similares, portanto, aos feitos ao Processo de Bolonha.

Na medida em que o REUNI provê as bases para a construção de um modelo de educação superior no setor público, pode-se antever que isso também implique mudanças de 'arquitetura' do sistema, num alinhamento 'casualmente proposital' com Bolonha. Além disso, Paula (2009) argumenta que a análise de políticas para a educação superior do governo federal permite ver nas aproximações, por exemplo, com o Processo de Bolonha, mecanismos para o aligeiramento da formação universitária e para a reversão de índices quantitativos de acesso à educação superior sem a devida atenção, no entanto, à qualidade e relevância social que dela se espera.

Podemos acrescentar ainda às convergências com Bolonha, aquelas relativas ao sistema de avaliação e garantia de qualidade. Em que pesem diferenças evidentes entre a construção do SINAES (Sistema Nacional de Avaliação da Educação Superior) e os referenciais de avaliação de Bolonha, o delineamento estrutural de ambos

${ }^{5}$ Projeto de Lei de Reforma do Ensino Superior - PL 7200/2006. 
pauta uma distinção entre os processos de avaliação e de regulação, uma organização top-down com implementação ao nível institucional e um movimento de interação constante entre auto-avaliação e avaliação externa.

Sinteticamente, presumimos que a conjuntura e o contexto atuais da educação superior brasileira tomam lugar num momento histórico de internacionalização da educação, de modo geral e da educação superior, em particular. Tal momento, por sua vez, é pautado em larga escala por processos regulatórios indissociados de processos avaliativos. Em relação a isso, pode-se presumir também que a opção brasileira (ainda que definida mais nitidamente por uma práxis do que pela asserção teórica) constitui, sob vários aspectos, um alinhamento com Bolonha. A questão da internacionalização a qual nos referimos é, por si só, controversa, principalmente pelas múltiplas semioses que o termo comporta.

Por outro lado, os eventos e ações no contexto global são cada vez mais interdependentes. No entanto, a relação entre local e global assume, nesse contexto, diferentes formas e perspectivas - algumas delas, inclusive, muito perversas. Nossa compreensão, no que concerne a isso é a da necessidade de uma relação dinâmica entre local e global, conforme o argumento de Santos (2006, p. 154) em que "pode-se afirmar que a diversidade epistêmica do mundo é potencialmente infinita, pois todos os conhecimentos são contextuais e parciais. Não há nem conhecimentos puros, nem conhecimentos completos, há constelações de conhecimentos", a consciência potencializa a construção de novas referências sobre estar e agir neste mundo complexo.

A construção da sociedade brasileira - é bom lembrar - está indissociavelmente ligada a um projeto de expansão europeia pós-idade média e o delineamento da identidade nacional é, em larga escala, resultante desse processo, caracteristicamente de expropriação e negação dos povos e culturas nativas em nome de um pretenso processo civilizatório (LANDER, 2005). 0 contexto sociopolítico mundial do atual momento histórico tem evidenciado uma lógica de mundialização das principais questões e dilemas enfrentados pela humanidade, embora a partir de uma perspectiva que define a relevância da agenda a partir dos atores que a propõem. Essa lógica implica a busca de confluências e alinhamentos e, nesse sentido, 0 Processo de Bolonha pode ser visto como um exemplo prototípico de unidade a partir de uma diversidade europeia e, portanto, relativa ou limitada.

Na medida em que tal processo tem como meta a construção de uma Europa do conhecimento pautada na qualidade e na mobilidade, de algum modo se apresenta também não apenas como uma ideia europeia de educação superior, mas como um modelo para o mundo, tal qual o Comunicado de Londres (BOLOGNA..., 2007) permite antever, ao reportar um alinhamento de vários países com o Processo de Bolonha ${ }^{6}$.

\footnotetext{
${ }^{6}$ No texto original do comunicado "Moreover, we acknowledge that efforts have been made in some countries in other parts of the world to bring their higher education systems more closely into line with the Bologna framework".
} 
A partir dessas configurações cabe questionar em que medida a educação superior brasileira está implicada nesse processo. Entendemos que a resposta a este questionamento passa necessariamente por um debate explícito sobre os significados potenciais de um alinhamento com qualquer que seja o modelo proposto e até mesmo ao que esse modelo - na prática -, nega.

\section{Considerações finais}

Ao longo do texto, procuramos explicitar não somente as origens históricas do Processo de Bolonha, mas, de modo especial, os significados dessas origens e do Processo em termos da racionalidade que ele representa. Além disso, procuramos situar o atual momento histórico da educação superior brasileira, no que diz respeito aos alinhamentos e convergências desta com o cenário mundial.

Se os impactos do Processo de Bolonha efetivamente passarem a ter mais relevo e importância no cenário mundial (e há razões de sobra para não duvidar disso), é fundamental sublinhar que o principal objetivo de tal movimento da educação superior europeia é restaurar a Europa como modelo para o mundo, com tudo que isso possa implicar. É importante, de igual modo, ter em mente que paralelamente aos movimentos do cenário europeu, também está posta a questão das novas (ou renovadas) forças de mercado (dentre essas, o Oriente, os países emergentes, ou as distintas situações de crise da África e dos Estados Unidos), no contexto das relações dinâmicas entre local e global.

Na medida em que a Europa manifesta o desejo de estabelecer parcerias internacionais que ampliem seu leque de opções para a educação superior, pode-se presumir que o filtro através do qual a pauta é depurada tende a apontar para os interesses da própria Europa. A condição de parceria, entretanto, exige uma postura de discussão e negociação que considere como basilares as noções de alteridade e diversidade.

É importante também resistir à tentação de - em nome da pretensa necessidade de internacionalização - assumir posturas que tem como matéria prima a supressão do debate, da contradição e até mesmo da consideração das experiências sistematicamente excluídas de pauta. A universidade - seja ela europeia ou brasileira - deve exercer, pois, na plenitude sua condição de locus privilegiado de análise crítica, propositiva e, sobretudo, prospectiva. 


\section{Referências}

APPLE, M. Ideologia e currículo. 3. ed. Porto Alegre: ArtMed, 2007.

BASTOS, C. C. B. C. 0 Processo de Bolonha no espaço europeu e a reforma universitária brasileira. Educação Temática Digital, Brasilia, DF, p. 95-106, 18 jan. 2008. Disponivel em: $<$ http://143.106.58.55/revista/viewarticle.php?id=462>. Acesso em: 14 maio 2008.

BOLOGNA PROCESS. About the Bologna Process. Louvain-la-Neuve, Belgium, 2009. Disponivel em: <http://www.ond.vlaanderen.be/hogeronderwijs/bologna/ about/>. Acesso em: 21 jun. 2010.

.The Bologna Process 2020: the European Higher Education Area in the new decade. In: CONFERENCE OF EUROPEAN MINISTERS RESPONSIBLE FOR HIGHER EDUCATION, 2009, Leuven and Louvain-la-Neuve. Communiqué of the... Leuven and Louvain-la-Neuve, 2009. Disponivel em: <http:// www.ond.vlaanderen.be/hogeronderwijs/bologna/conference/documents/ Leuven_Louvain-la-Neuve_Communiqué_April_2009.pdf>. Acesso em: 10 jul. 2009.

The European Higher Education Area: achieving the goals: Communiqué of the Conference of European Ministers Responsible for Higher Education. Bergen, 2005. Disponivel em: <http://www.dges.mctes.pt/NR/rdonlyres/ F9136466-2163-4BE3-AF08-C0C0FC1FF805/392/BergenCommunique1.pdf>. Acesso em: 10 jul. 2009.

. London communiqué: towards the European Higher Education Area: responding to challenges in a globalised world. London, 2007. Disponivel em: $<$ http://www.dges.mctes.pt/NR/rdonlyres/F9136466-2163-4BE3-AF08C0C0FC1FF805/391/LondonCommunique.pdf>. Acesso em: 10 jul. 2009.

BURBULES, N.; TORRES, C. A. (Org.). Globalização e educação: perspectivas críticas. Porto Alegre: ArtMed, 2004.

A CAMINHO da área europeia de ensino superior: comunicado do Encontro dos Ministros Europeus do Ensino Superior. Praga, 2001. Comunicado de Praga. Disponivel em: <http://www.dges.mctes.pt/NR/rdonlyres/F9136466-2163-4BE3AF08-C0COFC1FF805/551/Declaracao_de_Praga.pdf>. Acesso em: 10 jul. 2009.

CARR, D. El sentido de la educación: una introducción a la filosofía y a la teoria de la educación de la enseñanza. Barcelona: Graó, 2003. 
DECLARAÇÃO de Bolonha: declaração conjunta dos ministros da educação europeus, assinada em Bolonha. Bolonha, 1999. Disponivel em: <http:// www.dges.mctes.pt/NR/rdonlyres/F9136466-2163-4BE3-AF08-COCOFC1FF805/ 394/Declaracao_Bolonha_portugues.pdf>. Acesso em: 10 jul. 2009.

DIAS SOBRINHO, J. Processo de Bolonha. Educação Temática Digital, Brasilia, DF, p.107-132, 18 jan. 2008. Disponível em: <http://143.106.58.55/revista/ viewarticle.php?id=452>. Acesso em: 14 maio 2008.

ERICHSEN, H. U. Tendências europeias na graduação e na garantia da qualidade. Sociologias, Porto Alegre, ano 9, n. 17, , p. 22-49, jan./jun. 2007.

EUROPA: o portal da União Europeia. [S.I.: s.n.], 2010. Disponivel em: <http:// europa.eu/index_pt.htm>. Acesso em: 21 jun. 2010.

HARGREAVES, A. et al. Aprendendo a mudar: o ensino para além dos conteúdos e da padronização. Porto Alegre: Artmed, 2002.

KETTUNEN, J.; KANTOLA, M. The implementation of the Bolonha Process. Tertiary Education and Management, New York, v. 12, p. 257-267, 2006.

LANDER, E. Ciências sociais: saberes coloniais e eurocêntricos. In: (Org.). A colonialidade do saber: eurocentrismo e ciências sociais: perspectivas latinoamericanas. Buenos Aires: CLACSO, 2005. (Colección Sur Sur).

LIMA, L. C.; AZEVEDO, M. L. N.; CATANI, A. M. 0 processo de Bolonha, a avaliação da educação superior e algumas considerações sobre a Universidade Nova. Avaliação, Sorocaba, SP, v. 13, n. 1, mar. 2008. Disponivel em: <http:// www.scielo.br/scielo.php?script=sci_arttext\&tpid=S141440772008000100002 t Ing=pt\&nrm=iso >. Acesso em: 10 jul. 2009.

PAULA, M. F. A formação universitária no Brasil: concepções e influências. Avaliação, Sorocaba, SP, v. 14, n. 1, p. 71-84, mar. 2009.

POPKEWITZ, T. S. ; BRENNAN, M. Foucault's challenge: discourse, knowledge, and power in education. New York: Teachers College Press, 1998.

PORTUGAL. Ministério da Ciência Tecnologia e Ensino Superior. Direcção Geral do Ensino Superior. O Processo de Bolonha. Lisboa, 2008. Disponivel em: <http:// www.dges.mctes.pt/DGES/pt/Estudantes/Processo+de+Bolonha/ Processo+de+Bolonha/>. Acesso em: 21 jun. 2010. 
PORTUGAL. Conferência de Ministros Responsáveis pelo Ensino Superior: Comunicado [de Berlim]. Lisboa, 2003. Disponivel em: <http:// www.dges.mctes.pt/NR/rdonlyres/F9136466-2163-4BE3-AF08-C0C0FC1FF805/ 393/ComunicadodeBerlim 1.pdf>. Acesso em: 10 jul. 2009.

SANTOS, B. S. A crítica da razão indolente: contra o desperdício da experiência. São Paulo: Cortez, 2000.

. Um discurso sobre as ciências. 9. ed. Porto: Edições Afrontamento, 1997.

. A gramática do tempo: para uma nova cultura política. São Paulo:

Cortez, 2006. (Coleção para um novo senso comum; v. 4).

SORBONNE: déclaration conjointe. Paris, 1998. Disponivel em: <http:// devel.mctes.pt/archive/doc/Declaracao_da_Sorbonne.pdf>. Acesso em: 10 jul. 2009.

TUNING educational structures in Europe. Gronigen; Deusto, ES, 2000. Disponivel em: <http://tuning.unideusto.org/tuningeu/>. Acesso em: 10 jul. 2009.

VEIGA, A.; AMARAL, A. The open method of coordination and the implementation of the Bolonha Process. Tertiary Education and Management, v. 12, p. 283-295, 2006.

Recebido em: 12/02/2009

Aceito para publicação em: 11/01/2010 